\title{
China Market Entry Strategy Of Paris Baguette
}

Sungmin Ryu, Sungkyunkwan University, South Korea

Woojung Jang, Far East University, South Korea

HyeJeong Cho, Sungkyunkwan University, South Korea

\begin{abstract}
This case study analyzes the global strategy of Paris Baguette, a leading bakery franchise in Korea. Because of stricter regulations in the local market, Paris Baguette has encouraged franchises to target overseas markets. The company made first inroads into the Chinese market in 2004 with a bakery cafe in Shanghai. The main point of Paris Baguette's global strategy is summarized by high quality, style, diversification, and localization. Also, Paris Baguette directly operates its flagship store from headquarters, due to the poor legal environment in China. In this study, we analyze strategies of China market and suggest considerations for future business expansion.
\end{abstract}

Keywords: Bakery Franchise; Paris Baguette; China Market Strategy

\section{INTRODUCTION}

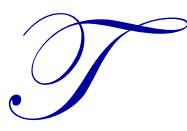

he franchise system operates as follows: The franchisee sells the franchisor's products or services, trades under the franchisor's trademark or trade name, and benefits from the franchisor's help and support. These features make it relatively easy for a franchise to go global. For example, report from KOTRA said approximately 30,000 McDonald's outlets in 120 countries were opened through franchising in 2010. However, the franchise system has been limited in its entry into overseas markets due to a lack of information or professional employees. For example, in the case of Korea, franchisors have opened only 60 overseas outlets out of 2,400 franchisors that exist in Korea.

Eight years after opening its first outlets in Shanghai in 2004, Paris Baguette became the first Korean bakery franchise to have 113 outlets in China. In addition to its several stores already in the U. S., Paris Baguette aims to increase the number of its branches there, including in Los Angeles and New York. It recently opened one outlet in Singapore and eight outlets in Vietnam. The Fair Trade Commission (FTC) took action on trading standards, banning bakeries from opening a franchise within a 500-meter radius of their stores. Following this, the Korean National Commissions for Corporate Partnership (NCCP) issued a regulation prohibiting new franchise store openings within a radius of 500 meters from a local bakery (Go, 2009). Likewise, the local franchise business faces a new environment that requires franchises to modify their expansion strategy and look toward international markets for sales.

This paper describes the issues confronting Paris Baguette's international growth strategy: 1) How can businesses adapt local practices to fit easily into the new environment?; 2) Who are the target customers?; 3) Should Paris Baguette follow the domestic positioning strategy in the China market?

\section{FRANCHISE BUSINESS ENVIRONMENT IN CHINA}

Since China's franchise business is in the early stages, various problems have arisen. For example, BreadTalk, a bakery franchise adopting a master plan franchise strategy, negatively influenced its brand because of a lack of thoroughness in the management of its franchisees. In Syenyang, a franchisee-owner assaulted a reporter for an article that was unfavorable to the franchise. Although the issue was resolved, word spread and had negative consequences. This problem has not disappeared, because follow-up management of franchisees is still deficient. 
Regulation itself is stricter in China than it is in Korea. Taking a look at differences, easy entry, and difficult survival are pervasive in Korea, whereas strict regulations exist in China, where high barriers of entry exist because it costs an enormous amount of capital to meet the requirements of the many strict regulations. In terms of loyalty, no franchisor demands loyalty yet, because imposing loyalty results in a disadvantage in competition with similar franchise headquarters. The Chinese franchise business shows that a franchisor makes revenues through the initial franchise fee, which is similar to the Korean franchise environment.

In China, each local government has an organization that attracts foreign investment in China's manufacturing facilities. At first, a local government provides tax benefits and low rent, but it increases the rent by ten percent every year. Over time, this has created an unfriendly business environment for foreign companies in China. In addition, overall manufacturing conditions have gotten worse. For example, the price of electricity is almost two to three times as much as it is in Korea (Lee, 2012).

Considering that bakeries require a number of workers and that wages also increase by ten percent every year, the business environment has become disadvantageous to foreign bakery franchises. Thus, many firms that considered China a manufacturing hub for low labor cost and targeted markets outside China have faced difficulties. This shows that an export system that targets a third country based on the viewpoint that China is the world's manufacturing hub, is no longer effective (Shin, 2013). On the other hand, firms that aimed for the Chinese domestic market and pioneered show relatively good results. Because rising of labor costs results in promotion of consumption, it'll be a good opportunity for these companies.

In addition, as China industrializes, the notion of a permanent job has become diluted. A relatively high turnover rate has been reported. Franchise stores require a number of employees for operation. The number of employees required per store is greater in China than it is in Korea. This is due to a deficiency in systematic employee training that has resulted from a high turnover rate. For example, in the case of local Chinese bakery franchises, employees in bread bakery lines make only breads, while those in cake bakery lines make only cakes, and those in sandwich lines make only sandwiches. In Korea, one employee is required to multitask, for the most part. When considering that China's wage system hikes up every year, hiring a number of employees is a detriment to revenue creation. Thus, the franchise business is expected to suffer disadvantages through not only human resource management, but also through rapid wage increases.

\section{BAKERY INDUSTRY: CHINESE CONSUMER ANALYSIS}

The Chinese bakery market provides a far more favorable environment than the Korean market does, including the following: First, bread is a staple food and a substitute for other staple foods. Although Chinese people do not eat bread at every meal, they do consider it one of the substitutes for other staples. However, since Koreans think of bread as a snack, the eating pattern of the Chinese provides a much more favorable environment for sales growth of the baking industry than it does in Korea.

Second, the breakfast-eating-out market is strong in China. Most Chinese people do not make breakfast at home. Thus, one sees people buying street food and eating on the way to work. They usually have 'mantou' from convenience stores, 'babimantou' from licensed street vendors, or other foods ('mantou,' 50 percent; 'youtiao,' 30 percent; and bread, 20 percent) from unlicensed street vendors. Kentucky Fried Chicken (KFC) offers a breakfast menu with local foods such as 'congee' and 'youtiao.' Bakery franchises have also started to target the breakfast market by creating breakfast menus.

Third, people in Korea have the perception that bread is an unhealthy food, whereas the Chinese do not. The reason why many Chinese people choose bread for their dinner is the fact that the perception of bread is more favorable in China than it is in Korea. This is the basis for possible swift sales growth in China in the future.

In conclusion, among the factors mentioned, we couldn't find other factors except for bread as a breakfast substitute in Korea. Considering these environmental conditions, China is viewed as a bakery market of potential compared to Korea. 


\section{BAKERY MARKET TREND IN CHINA}

China's baking food industry is expected to reach a market size of 130 billion yuan in 2013, and it shows 20 percent annual growth (Choi, 2013). China's government divided cities into levels from the largest 1 level to the smallest 6 level. City levels will be fixed according to political, social, and economic factors, especially, since China's baking industry usually develops in the 1 and 2 level cities. China has recently exhibited good conditions for the development of the baking industry, a Western food industry, because of increases in household income and international exchange growth (Zhū, 2009).The baking industry of China is an emerging business that has enormous potential for development in the future not only because of traditional Chinese food, but characteristics of the Chinese people, who accept Western foods and enjoy them.

Four companies, Marco Polo, Christine, Yuanzu, and Kosongbang are pioneers that developed China's bakery market, which sold factory mass production bread at supermarkets. The modern baking industry started in China in the 1980s, when Taiwanese baking companies entered the market. In the 1990s, since the relationship between China and Taiwan resolved, many more Taiwanese baking companies entered the market. They began to expand their market from Fujien Sheng to the northern part of China in the early 1990s. In 2003, more upscale brands such as BreadTalk, Paris Baguette, and Yamazaki started to penetrate the market, and Chinese local brands also started to grow.

The bakery industry of China exhibits three characteristics. First, although competition is intensifying, no strong player exists yet. Small and medium-sized local companies in each region show high market shares (which is reminiscent of the period of warring states in ancient China), and a nationwide brand does not exist in the market. There are leaders that show a high market share in each region, for example, Holiland in Beijing, Christine in Shanghai, Qinyuan in Chongqing, Hunagguan in Wuhan, and Jinleyuan in Tianjin, because these companies usually adopt a strategy of expansion to markets neighboring the regions where the companies were established. In addition, no companies that cover the whole mainland China market exist because of problems regarding production, distribution, and logistics. Although Paris Baguette, $85^{\circ} \mathrm{C}$, and Marco Polo try to adopt nationwide expansion strategies, they have not shown impressive market coverage through store expansion.

Second, the percentage of directly managed stores is high except for a few companies. Direct management of stores, which allows headquarters to have full control and management rights over a store through direct investment in it, has advantages as a marketing strategy. However, only companies that have funding power are able to realize it, because of the enormous costs involved. In the case of Paris Baguette, only 6 out of 105 stores are franchisees. Holiland and Christine, which are the top one and two local companies, respectively, have expanded stores through direct management.

The third characteristic is that baking companies have attempted various sales strategies. For example, many companies provide an online or telephone order system for customers' convenience. Holiland and Paris Baguette have started bakery cafés. Although this attempt is in its early stages, it is expected to grow gradually.

A summary analysis of the Chinese bakery market suggests that the China market has great potential because the market has not entered its stage of maturity. Since technological entry barriers are low in China, second movers that are competitive also have a good chance of success. Thus, the Chinese market provides an environment in which Paris Baguette can compete favorably, using its know-how from the Korean market, such as baking technology and the capability for managing thousands of stores.

\section{COMPETITION}

\section{Foreign Competitors}

$85^{\circ} \mathrm{C}$ (Taiwan)

$85^{\circ} \mathrm{C}$ opened its first store in Shanghai and currently runs a total of 500 stores, with an aggressive expansion strategy in Suzhou, Hangzhou, Beijing, and other locations nationwide. $85^{\circ} \mathrm{C}$ ranks first in terms of sales 
among foreign baking companies, and, to keep its current status, plans to open a total of 1,000 stores within six years by increasing the number of stores in main cities such as Beijing, Chongqing, and Shenzhen, with the Huadong area as its center.

Its interior design is not ideal, but $85^{\circ} \mathrm{C}$ provides a comfortable atmosphere. For customer accessibility, the bakery is a 24 -hour café style. Although $85^{\circ} \mathrm{C}$ is a Taiwanese company, its taste is localized for Chinese customers. Its coffee sales account for about 25 percent of total sales, which is relatively high (bread $45 \%$, cakes $30 \%$, and coffee 25\%). Its average price is relatively inexpensive (coffee, 8 yuan; bread, 3 to 6 yuan; a piece of cake, and 8 yuan). This is because $85^{\circ} \mathrm{C}$ targets lower middle-class customers.

\section{BreadTalk (Singapore)}

Since BreadTalk entered the Chinese market, it has opened 171 stores, and has expanded steadily, especially in big cities such as Shanghai and Beijing. BreadTalk targets cities with master franchise strategy. It uses storytelling about names of bread that are related to the taste and feeling of bread. These help customers understand brand better. Its interior design provides a clean and neat atmosphere, usually with marble, stainless steel, and glass. In addition, to emphasize its neatness and cleanliness, the kitchen is visible through glass, so that customers can see the baking process in the store.

\section{ICHIDO (Japan)}

Since ICHIDO opened its first store in Shanghai, it now has 37 stores in Jiangsu, Liaoning, etc. ICHIDO provides three types of products: Chinese, Western, and Japanese, under the principle of daily produced bread. Its product is appreciated for its non-greasiness and moderate sweetness and for its emphasis on R\&D efforts, and it was selected as 'one of the top 10 most popular bakeries in China' at the end of 2008, and 'Shanghai's best bakery' at the end of 2009. ICHIDO targets upper middle-class customers and has become a direct competitor of Paris Baguette.

\section{Local Competitors}

Many local baking companies in China are regional businesses, and there are many competitors in each region. First, Holiland which does business mainly in Beijing and shows annual sales reaching two billion yuan, is the top bakery in China. Holiland started business in the northeast market of China, and now owns about 1,000 direct management stores in about 70 medium and large-sized cities, including Beijing. Based on the principle that customers do not travel long distances to purchase bread, it has focused on aggressive store expansion. Holiland's main products are: cake, bread, yuebing, ad TanyuanXain (Chinese small dumpling), and the average price is inexpensive, targeting lower middle-class customers (cake, 200 yuan; bread, 3 to 8 yuan; and coffee, 8 yuan).

Christine started business in Shanghai and now owns about 800 stores in the Yangtz River Delta area. Christine, which was the first company to obtain a certification of ISO9001 for quality management and Hazard Analysis and Critical Control Point (HACCP) for food safety, is well known for its modernized information technology (IT), management system, and facilities.

Qinyuan which covers the southwest area, including Chongqing, has 40 percent of bakery products market share in Chongqing area. It now owns about 200 stores, which are all direct sales stores without franchisees or dealers. Jinleyuan started in Tianjin, and owns about 70 stores, mainly in the Tianjin and Tanghsan area. It claims the 'three plus three healthy rule,' which is 'high calcium, high protein, high vitamin, plus low sugar, low fat, low cholesterol,' and the rule is applied to all products of Jinleyuan. It is rated an excellent firm in various sectors such as 'China's Best Brand,' 'Best Safe Yuebing,' 'Renowned Yuebing Manufacturing Company,' and 'National Best Bakery,' and it is well known for relatively high technology.

In China's baking industry, there is no nationwide company yet, and regional companies each focus on a particular area. This is due to each baking company's limited logistical capacity to cover the wide mainland of China. 


\section{PARIS BAGUETTE IN CHINA}

\section{Target Market}

Currently, China's average per capita income is over $\$ 5,000$. Cung-Ang News estimates that the middle class in China $(\$ 16,000 \sim 34,000)$ comprise approximately $6 \%$ of the population, which is $14,000,000$ households, and the upper class (> \$34,000) comprise about $2 \%$, and both are rapidly increasing. Paris Baguette aims to attract these people as their targeted customers.

According to the Institute for International Economics Research, the middle class in China spends 25\% of their income on groceries, accounting for a large part of their expenditures. Dining-out consumes $10 \%$ of their income because most Chinese do not usually have breakfast at home (see Table 1). Considering the high percentage of meals eaten out and the increasing average income in China, Paris Baguette needs to focus on their target customers' consumption characteristics, especially regarding baked goods.

Table 1: Chinese Consumption Characteristics

\begin{tabular}{|l|c|c|c|}
\hline \multicolumn{1}{|c|}{ Type of Consumption } & The Upper Class & The Middle Class & The Lower Class \\
\hline Food and Beverage & $13 \%$ & $36 \%$ & $53 \%$ \\
\hline Daily Supplies & $9 \%$ & $5 \%$ & $5 \%$ \\
\hline Medical & $4 \%$ & $6 \%$ & $5 \%$ \\
\hline Education & $8 \%$ & $10 \%$ & $10 \%$ \\
\hline Shopping & $31 \%$ & $16 \%$ & $11 \%$ \\
\hline Dining out & $17 \%$ & $12 \%$ & $7 \%$ \\
\hline Entertainment & $10 \%$ & $6 \%$ & $6 \%$ \\
\hline Other & $8 \%$ & $9 \%$ & $3 \%$ \\
\hline
\end{tabular}

Source: Mckinsey Inisght China, 2009

\section{Core Strategy}

Going Beyond High Quality

Paris Baguette pursues a 'Going beyond High Quality' strategy. It is not only related to brand image and sales channel, but also greatly relevant to design distribution channel. Therefore, Paris Baguette has selected their sales channels such as center of the major city, department stores, or big shopping mall to match with their desired brand image.

In addition, Paris Baguette operates franchises in wealthy villages of major cities in China. For example, Daning is one of the popular downtowns in Shanghai. Paris Baguette has opened a store at the biggest shopping mall in Daning and impressed with their high quality brand images. Moreover, they have been a part of the famous shopping mall in Beijing called 'The Place.'

The Chinese people have come to prefer premium brands and safe food. Therefore, Paris Baguette has continuously focused on opening its flagships in downtown areas or in big shopping malls in the city. The Paris Baguette chain has appealed to local customers with a premium image by opening its outlets with modern ambiance, mostly in downtown areas and well-off residential districts. In addition, it has adopted the 'bake-off' system, under which frozen dough is baked at individual stores so that customers can purchase fresh items baked that day.

Since its establishment in China, Paris Baguette has been winning recognition and various awards, such as the Beijing Reputation Bakery Award, the Top 10 Cake Shop Award and the Five-Star Bakery Award, and it is poised to hold a dominant position in China (Hyun, 2011). After Paris Baguette's premium brand image was established, Hisense plaza in Tianjin offered to open a branch of Paris Baguette, under the condition of free rental for two years. It is one of the examples that have validated Paris Baguette's strategy. 


\section{Diversification}

Paris Baguette in China enjoys a dominant position by providing a diversity of products, compared with competitors. To attract more customers, Paris Baguette offers diverse products and a wide range of product options. However, the total cost has greatly increased, due to the rising administrative costs of diversification. Even if total cost goes up, Paris Baguette has continuously provided a variety of products to achieve customer satisfaction and to maintain its well-earned reputation.

\section{Localization}

Paris Baguette is a significant example of planning a global strategy to adapt to China's own special culture called 'GuanXi.' For example, one of the world's leading bakery companies, named 'Fauchon,' opened its flagship store in Shanghai, but they failed to fulfill local customers' preferences. The plan ended in failure before two years had passed (Choi, 2013).

Paris Baguette has focused on producing a bread to suit the unique Chinese taste. For example, Rou-Song is a popular food item in Chinese culture, usually used as a topping for food. Paris Baguette has begun to produce RouSong bread, and it is becoming increasingly popular in China. In fact, currently, 20\% of displayed products at Paris Baguette in China are products localized for Chinese. Paris Baguette tries to encourage the Chinese to gradually accustom themselves to Korean style. For this reason, $80 \%$ of displayed products are purely Korean style. It is one of the ways to maintain Paris Baguette's unique brand and to differentiate itself from the competition.

Another localization strategy is to have Chinese-style brand names. The brand name of China Paris Baguette is loved by many Chinese people for its friendly nuance and its feeling of good will.

\section{ADOPTION OF FRANCHISING}

Paris Baguette opened its first flagship store in Shanghai in June 2012, and they are accelerating their chain expansion in China by taking a cautious approach in order to maintain quality and their service management strategy. This is why, given the poor legal environment in China, Paris Baguette currently operates 46 stores, but only 6 stores are franchisees. In China, franchisee driven expansion is still a risk because there are conflicts between franchisor and franchisee. For example, CaffeBene recruited its franchise in China in order to begin its entry into the Chinese market. However, the franchisee in China was operating under its own authority, and this finally led to the termination of the franchising.

Financing is usually the first major obstacle to expanding an international franchise business. Chinese financing firms preferred large enterprise company in lending. Moreover China's government continuously strengthened regulation of funding in China. This caused the international franchise companies to have financial problems, with a low turnover of capital (Choi, 2013).

Likewise, Paris Baguette directly operates its flagship store from headquarters, due to the poor legal environment in China. However, there are some aspects of expanding franchisees at a fairly slow pace that need to be considered. Firstly, in the competitors' case, they have operated more than 200 outlets in Shanghai by using a franchise system. Even if Paris Baguette still holds a dominant position, a slow-paced strategy may be disadvantageous to dominate the main market. Tous Les Jours, a bakery brand in Korea, has also signed a master franchise deal with a Chinese company in SiChuan territory as the outpost for their Chinese market expansion. Secondly, using slow-paced franchisee expansion, it is hard to get a good franchisee. For example, if competitors recruit a potential franchisee, Paris Baguette may difficult to finding good franchisees.

In Paris Baguette, the managers of headquarters-operated stores comprise $100 \%$ local Chinese. If Paris Baguette begins a franchise operation aggressively, these Chinese employees become potential owners of franchisees. They are already experienced in operations, and they are capable of taking these stores to the height of success in the near future. 


\section{A RELATIONSHIP BETWEEN SUPPLIER AND MANUFACTURER}

Paris Baguette in China uses local ingredients and raw materials. The most important thing is for raw materials to match the specifications of Korean headquarters. They have to cut back on unit costs as compared to headquarters, raw material cost, and the cost of ingredients. However, Paris Baguette can't expect to get a merit for purchasing cost because labor costs or rental costs aren't lower than in Korea.

Dormant dough is given great importance, due to the Chinese preference for freshly baked bread. To retain freshness, they supply dormant dough from the factory. Paris Baguette has established their factory in the field to produce and supply the product directly, the same as is done in Korea. While headquarters in Korea uses vertical integration, the Chinese branch gets all materials from the supplying company. At first, there were many challenges to getting "on the same page" with the Chinese supplying company, but now they are there.

There are about 113 stores in China, so purchase amounts are currently comparatively low (see Table 2). Therefore, it is difficult to gain advantage from purchase amounts through low supply price. There is no contract period, but the bidding is highly competitive, so they are continually looking for a new company to do multiple trading. Even though terminating the contract with a supplying or manufacturing company, Paris Baguette gives them continuous opportunities for further business. The reason is that "GuanXi" (Guanxi refers to the dynamic influence of human networks, particularly in Chinese politics and the government) is extremely important in China's culture, so they have to leave open the possibility of doing business with them again.

Table 2: Number of Paris Baguette Stores in China

\begin{tabular}{|l|c|c|c|}
\hline Year & Number of Stores & Year & Number of Stores \\
\hline 2004 & 1 & 2010 & 46 \\
\hline 2005 & 5 & 2011 & 73 \\
\hline 2006 & 16 & 2012 & 104 \\
\hline 2007 & 24 & 2013 & 113 \\
\hline 2008 & 27 & 2015 & 200 \\
\hline 2009 & 31 & 2020 & 1,000 \\
\hline
\end{tabular}

Source: SPC group, 2013 (2015-2020 years refer to estimations).

\section{WHAT'S NEXT?}

In Korea, franchise policies are tightening up, banning bakery franchise stores from opening within a 500meter radius of a bakery of the same franchise. Furthermore, the policy bans forced promotion activities and putting pressure to pay advertising expenses on franchisees without their assent. With all these changes in environment, the two leading brands of Paris Baguette of SPC Group and Tous Les Jours of CJ Foodville Corp have encouraged franchises to target overseas markets. SPC Group said it is seeking to launch more than 1,000 bakeries abroad by 2015, up from its current 127, and expects an estimated 700 billion won (6,575 million dollars) from overseas sales; especially since franchise competition becomes more and more intense in China. China offers a lot of marketing opportunities in the bakery franchise business.

\section{CONCLUSION}

By entering the overseas market, Paris Baguette aims to increase its competitiveness. Paris Baguette currently has 80 outlets in China and plans to establish more than 100 outlets in overseas markets to become more global. It is comparatively easier for the franchise system to go global than it is for other businesses. However, the key is how to build a successful strategy in China, in consideration of their business environment, and this will determine the success or failure of the business.

Paris Baguette is operating according to a different strategy in the overseas market, and it consists of going beyond high quality strategy, diversification, and localization. At first, it differentiated itself by premium brand, targeting the upper class, and implementing experiential marketing to solidify brand image and increase brand recognition. Going beyond high quality strategy is closely related to designing a distribution channel, so Paris Baguette has mostly established its outlets in main cities, big shopping malls or department stores to fit its desired brand image. Another strategy is defined as diversification for entering the China market. The company provides a 
variety of products in order to gain a competitive advantage over rival companies. Offering a diversity of product is providing more choice to the customer as well as attracting them to visit the outlets. In addition, Paris Baguette has focused on developing localized products to suit unique Chinese tastes, such as Rou-Song Bread and skewered pastry. Currently, 20\% of displayed products at Paris Baguette in China are localized products for the Chinese. The company also supplies dormant dough from the factory to retain freshness.

However, Paris Baguette is faced with other problems. First, the expansion pace is quite slow. The number of franchisors is comparatively lower than franchises operated by headquarters. In terms of the features of franchisors, they have to consider building or re-appraising their growth strategy by franchising.

Lastly, the portion of localized product in China is one of the considerations. More than $80 \%$ of products are exactly the same products as those sold in Korea. Therefore, Paris Baguette would do better to determine the proper proportions of localized product and globalized product to place in the China market.

\section{CASE QUESTIONS}

1. Why do firms decide to enter the overseas market? Discuss the issues about local franchise business's environmental change.

2. What are Paris Baguette's strong points compared to competitors? What are Paris Baguette's weak points compared to competitors?

3. How can Paris Baguette reduce the risk that may arise in adopting franchise strategy in China?

4. What are the main points of Paris Baguette's global strategies?

\section{AUTHOR INFORMATION}

Sungmin Ryu is an associate professor of the School of Business at Sungkyunkwan University. He specializes in the areas of channels of distribution, business-to-business marketing, and global supply chain management. He has publications in Industrial Marketing Management, Journal of Business Research, Organization Science, Journal of Business and Industrial Marketing, Journal of Business-to-Business Marketing, and Journal of Marketing Channels, and others. E-mail: $\underline{\text { smryu @ skku.edu }}$

Woojung Jang is a professor at Far East University. She specializes in the area of distribution channels and business-to-business marketing. She has a publication in the Journal of Business Case Studies. E-mail: jangzzang77@ @anmail.net

Hye Jeong Cho holds a Ph.D in business and teaches at Sungkyunkwan University. She specializes in the areas of distribution channels and global supply chain management. She has publications in the Journal of Business Case Studies and Journal of Business-to-Business Marketing. E-mail: wf817@ naver.com (Corresponding author)

\section{REFERENCES}

1. Atsmon, Y., Ding, J., Dixit, V., Leibowitz, G., Magni, M., \& Zipser, D. (2009). 2009 Annual Chinese Consumer Study. Mckinsey Inisght China, 1-24.

2. Choi, H. (2013). Korean franchises capture Chinese tastes. KOTRA Report, 4, 51-57.

3. Go, S. (2009). War in alley business area expanded legal battles. MK Economy Newspaper. Retrieved from http://news.mk.co.kr/newsRead.php?year=2013\&no=95927

4. Hyun, K. (2011). Paris Baguette in SPC group become a global brand. Economy inside Newspaper. Retrieved from http://www.keconomy21.co.kr/sub_read.html?uid=3877

5. Lee, S.-W. (2012). It is no longer true to say that China's cheap labor. Yonhap Newspaper. Retrieved from http://news.naver.com/main/read.nhn?mode=LSD\&mid=shm\&sid1=101\&oid=001\&aid=0006193468

6. Shin, H. (2013). Growth rate of China is predicted to drop 5-6 percent within 5 years. Mail Economy Newspaper. Retrieved from http://news.mk.co.kr/newsRead.php?year=2013\&no=296020

7. Spc website. (2013). Retrieved from http://www.spc.co.kr/globalSPC_eng

8. Zhū Niàn Lín. (2009). The China baking food market research and development analysis report. Zhōngshāng qíngbàowăng. Retrieved from http://www.askci.com/ 


\section{TEACHING NOTES}

1. Why do firms decide to enter the overseas market? Discuss the issues about local franchise business's environmental change.

The transaction restriction policy of the FTC (The Fair Trade Commission) in Korea has imposed legal controls on rapid expansion of local franchises. Recently revised local trade laws that forbid businesses from opening new shops within a 500-meter radius of an existing bakery have encouraged franchises to target overseas markets. Under these circumstances, Paris Baguette and Tous Les Jours, under double regulation, forecast the number of stores decreasing by 50 to 60 annually and 300 to 360 stores shutting down over three years. The local franchise business has faced a new environment that requires franchises to modify their expansion strategy and look for other sources of sales.

Franchise business practices related to interior design are regulated. In most cases, a franchise headquarters is required to support 20 to 40 percent of expenses for interior renovation of franchisee stores. However, customary business conduct has changed dramatically. For example, store renovations, which previously had been done in accordance with custom, must now be done based on FTC's explicit criteria. According to bakery franchise trading standards, a franchise headquarters is not permitted to require a franchisee to renovate interior design without the franchisee's agreement. The franchisor is required to provide 40 percent of expenses for store relocation and expansion and 20 percent for general renovation.

The policy has also banned imposing advertising expenses on franchisees without their permission and forced promotion activities, such as credit card partner discounts. In terms of advertising and promotion, a franchise headquarters is prohibited from requiring promotional activities from a franchisee store that does not assent to it or provide prior agreement.

2. What are Paris Baguette's strong points compared to competitors? What are Paris Baguette's weak points compared to competitors?

Paris Baguette has formed a successful franchise business in Korea. Reaching $70 \%$ of the market share in bakery franchises, it has created an unparalleled record in the history of the bakery franchise industry. Likewise, achieving a high level of market share not only exerts a favorable influence on product development and store management, but also spurs useful know-how for getting into the China market. Through R\&D systems, Paris Baguette has succeeded at developing Chinese localized products such as O-Sung Bread, and these localized products comprise more than $20 \%$ of products on store shelves. Moreover, having a greater variety of stock products compared to competitors has resulted from outstanding product development.

Taiwanese and Singaporeans understand China better and have advantages among the Chinese people. For example, Taiwanese or Singaporean companies find it relatively easy to get business approval from the Chinese government, using China's own culture, called 'GuanXi.' This is a Chinese term for connections that can make or break business deals, personalized networks in Chinese society. Inevitably, Korean companies face disadvantages in this GuanXi culture of the Chinese market, compared to these other two countries.

3. How can Paris Baguette reduce the risk that may arise in adopting franchise strategy in China?

In order to export the franchise, Paris Baguette focused on company-owned business operations. Paris Baguette currently operates 46 stores, but only 6 stores are franchisees. Likewise, Paris Baguette directly operates its flagship store from headquarters, due to the poor legal environment in China. Also, another major reason for use of this strategy is very careful market research. It requires a more judicious approach to applying the new market. Illconsidered approach of franchise business increases risk of franchisee.

4. What are the main points of Paris Baguette's global strategies?

The main point of Paris Baguette's global strategy is summarized by high quality, style, diversification, and localization. Firstly, they differentiate themselves through creating premium brands that are intended for the upper 
class or for people who have high purchasing power. Secondly, they hold events for customers (experiential marketing) to improve brand recognition. Lastly, they introduce popular products based on developing new products in China. Approximately $20 \%$ of their products have been developed in China in recent times, and they provide a wider variety of products than their competitors, in order to maintain a dominant position. 